
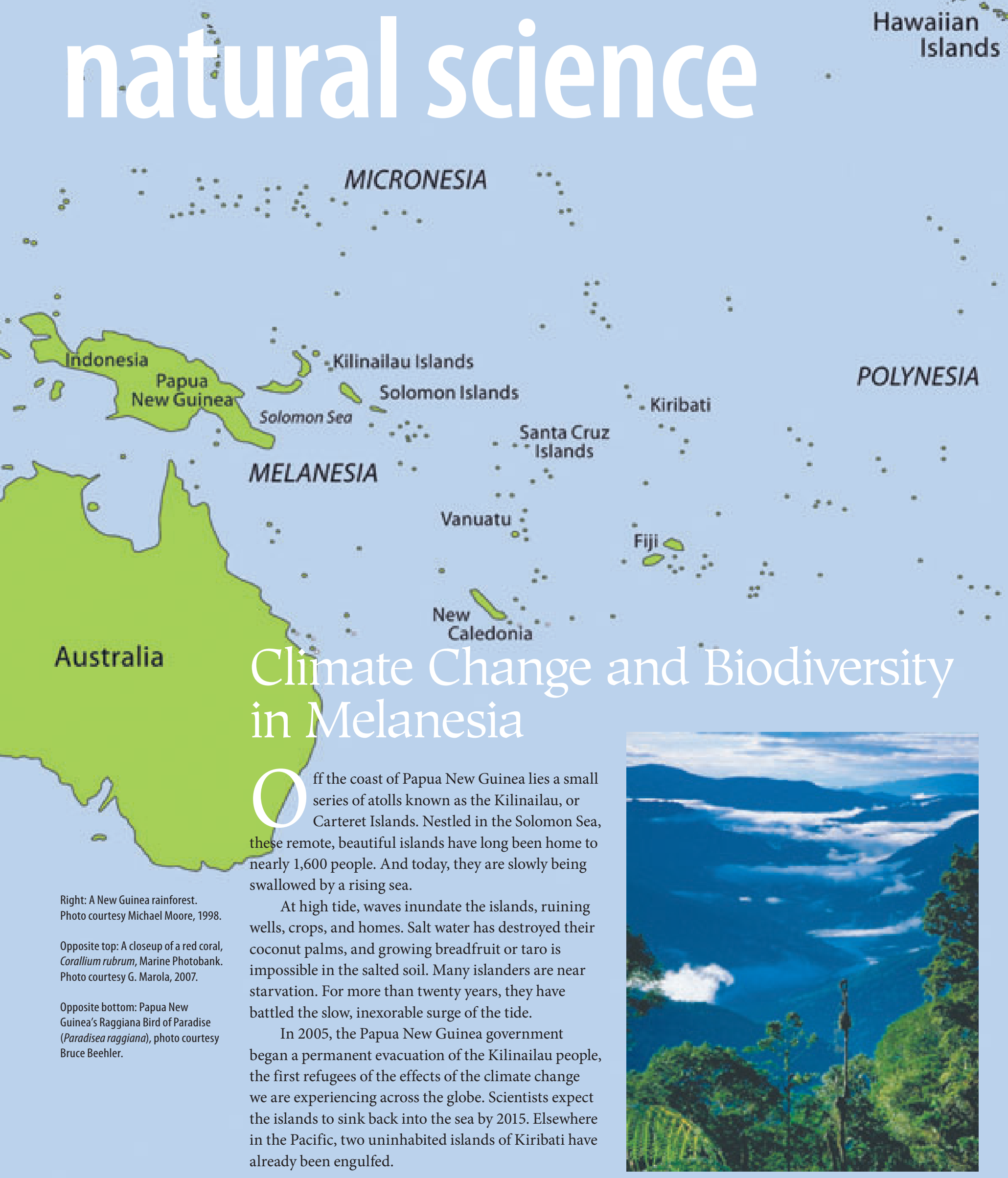
The global climate is changing, with a slow but steady warming trend over the past fifty years. And, the UN's Intergovernmental Panel on Climate Change (IPCC) - which shared the 2007 Nobel Peace Prize with former Vice President Al Gore-recently concluded that this temperature increasenow considered "unequivocal"-is very likely due to human activities. As temperatures increase and the sea levels rise accordingly, what the Kilinailau islanders face today may become more and more common. The rising sea levels will also have a devastating impact on the plants and animals that called Kilinailau home.

How will climate change impact human societies and biodiversity in the Pacific? Today, Bishop Museum scientists are working on this very question-one that is of increasing concern to Pacific Island communities. In 2007, Bishop Museum, in collaboration with the South Pacific

\section{Regional Environment}

Programme (SPREP), received a grant from the John D. and Catherine T. MacArthur Foundation to assess the vulnerability of island ecosystems in Melanesia in the face of projected climate changes. Museum scientists Dr. Allen Allison, Dr. Stephen Leisz, and John Burke Burnett are investigating the projected impacts of climate change on biodiversity in Melanesia, while researchers at SPREP study the institutional and socio-economic abilities of the countries of Melanesia-Papua New Guinea, Indonesia's Papua province, Solomon Islands, Vanuatu, New Caledonia, and Fiji-to adapt to the changing climate.
The island nations of Melanesia lie deep in the tropical western Pacific and are home to a breathtaking array of cultural and biological diversity. Melanesia's seas and coral reefs are the epicenter of the world's marine biodiversity, and its islands host some of the

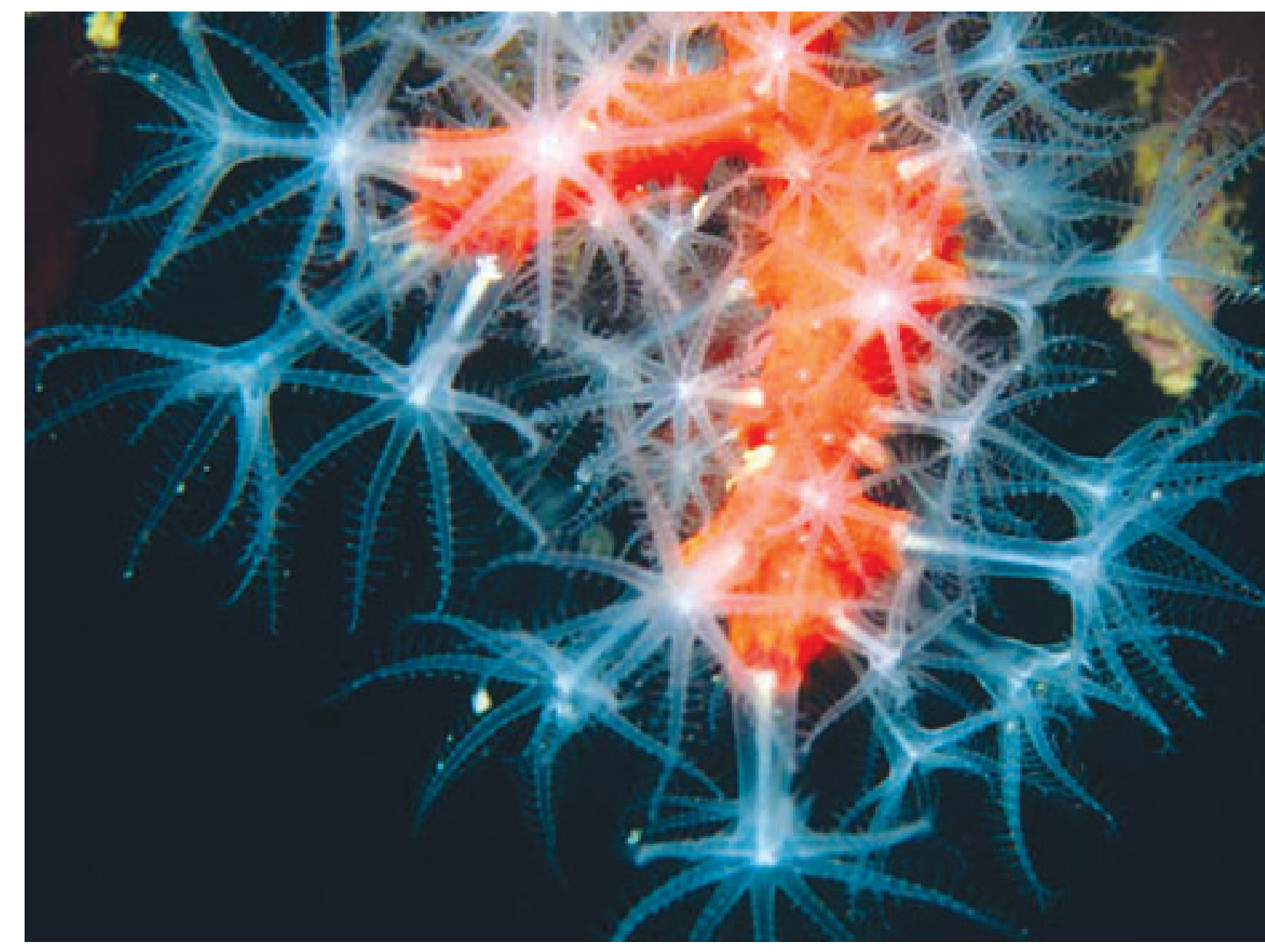

most diverse terrestrial ecosystems on the planet. Here, giant clams, birds of paradise, tree-climbing kangaroos, and over half of the world's species of coral can be found. This spectacular diversity makes Melanesia especially important; yet it is also exceptionally vulnerable to habitat degradation and habitat loss. Effective conservation strategies are essential to preserving Melanesia's rich natural resources. In order to be successful in the coming years, these strategies must also account for the impact of global climate change.

This past fall, a diverse group of scientists met on O'ahu to explore these topics. Climatologists and

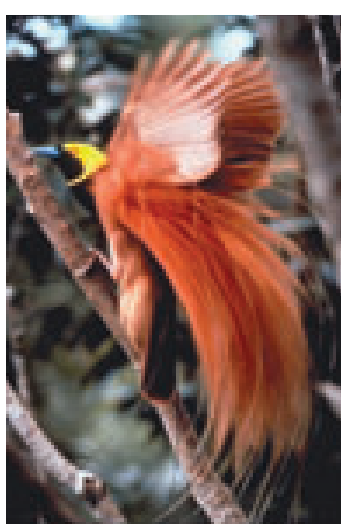


